OPEN ACCESS

Edited by:

Zhuolun Li,

Lanzhou University, China

Reviewed by

Ruijie Lu,

Beijing Normal University, China

Bing Liu,

Northwestern Institute of EcoEnvironment and Resources, China

Xin Gao,

Xinjiang Institute of Ecology and Geography (CAS), China

*Correspondence: Aimin Liang

aimliang@snnu.edu.cn

Specialty section:

This article was submitted to Quaternary Science, Geomorphology and Paleoenvironment, a section of the journal Frontiers in Earth Science

Received: 08 November 2021 Accepted: 01 December 2021

Published: 18 January 2022

Citation:

Dong P, Liang A and Zhou Y (2022) Advancement of Megadunes and its Implications in the Badain Jaran

Sand Sea.

Front. Earth Sci. 9:811181. doi: 10.3389/feart.2021.811181

\section{Advancement of Megadunes and its Implications in the Badain Jaran Sand Sea}

\author{
Peng Dong ${ }^{1,2}$, Aimin Liang $^{3 *}$ and Yali Zhou ${ }^{3}$ \\ ${ }^{1}$ College of Life Sciences, Hainan Normal University, Haikou, China, ${ }^{2}$ College of Geography and Environmental Science, Hainan \\ Normal University, Haikou, China, ${ }^{3}$ School of Geography and Tourism, Shaanxi Normal University, Xi'an, China
}

The tallest megadunes on the Earth are developed in China's Badain Jaran Sand Sea, as a result of which a prolonged curiosity exists with regards to the existence and migration of such large dunes. However, our present understanding of movement of aeolian bedforms is largely limited to dunes with height ranging from several to several tens of meters. Difficulties in understanding the movement of megadunes predominantly exists in the monitoring methods. This study presents the evidence of the megadune advancement and its rate in the Badain Jaran Sand Sea, estimated by optically stimulated luminescence (OSL) dating of sediments on the slipfaces of several megadunes. It is suggested that megadunes experience similar advancement as the commonly observed sand dunes; the rate of advancement of megadunes fits the rateheight relationship. The rate of advancement varies linearly with the reciprocal of megadune height, which has been confirmed for dunes, extending the advancement rate-height relationship to a previously blind range of dune size. In addition, the advancement rate of megadunes exhibits far-reaching implications for megadune formation. In combination with other morphometric evidences, it exemplifies the assumption that the development of megadunes is predominantly controlled by wind rather than other factors such as the underlying relief and ground water, as accepted by most researchers.

Keywords: dune geomorphology, dune movement, advance rate-height relationship, megadune formation, Badain Jaran Sand Sea

\section{INTRODUCTION}

Aeolian geomorphology has always attempted to understand the formation mechanism of aeolian bedforms that are organized into a hierarchical system consisting of ripples, dunes, and megadunes (i.e., large bedforms with a spacing exceeding $500 \mathrm{~m}$ and a height reaching 200 or $300 \mathrm{~m}$ and may occur as linear, crescentic, or star forms) (Wilson, 1972; Goudie, 2004; Livingstone and Warren, 2019). However, its development is unfavorable as the formation mechanism is highly differentiated by bedform scale, a behavior of nonlinear dynamical system (Phillips, 1992). It is now assumed that wind ripples are formed by air-particle movement interactions, dunes are developed through bedform-airflow feedback, and megadunes are possibly controlled by the thickness of atmospheric boundary layer. However, our understanding regarding the mechanism of aeolian bedforms is limited to selected dune types, typically barchan and linear dunes (Rozier et al., 2019; Qian et al., 2021). 
The formation mechanism of megadunes has to be speculated. For example, several hypotheses have been proposed with respect to the formation of megadunes in the Badain Jaran Sand Sea. The underlying relief hypothesis holds that the megadunes are formed by aeolian sand covering on topographic prominences (Lou, 1962; Sun and Sun, 1964); groundwater hypothesis supported that the megadunes are maintained by internal moisture, which is extracted from groundwater through capillary action (Chen et al., 2004); aeolian hypothesis advocated that the megadunes are formed by wind, just like the common dunes (Dong et al., 2009). On the other hand, attempts to relate ripples, dunes, and megadunes are never abandoned because they share several morphological similarities (Dong et al., 2009). The distinction between the formation mechanism of ripples and dunes has been verified by extensive study including field observation and physical and numerical simulation (Richards, 1980; Pelletier, 2009; Lämmel et al., 2018). In contrast, the relationship between the formation mechanism of dunes and megadunes remains unknown because limited studies have been conducted with respect to megadunes, which are generally compound to complex with the superimposition of dunes and ripples. Till date, the formation of megadunes can only be speculated subjectively or based on a few weak evidences because it is not feasible to study megadunes like ripples and dunes (Dong et al., 2013). It is assumed that the similarity between megadunes and dunes should be implied in various aspects besides morphology. The analysis pertaining to Dong et al. (2009) on the geomorphological patterns characterized by height-spacing relationship of megadunes suggests that this relationship is consistent with superimposed dunes and wind ripples, and also with dunes and wind ripples distributed globally over the sand seas. It is therefore deduced that wind is predominantly responsible for the development of megadunes in the Badain Jaran Sand Sea. However, this deduction regarding the formation of megadune requires further evidences.

Mobility is the most conspicuous property of shifting dunes, although the overall activity varies as per different dune types (Thomas, 1992; Livingstone and Warren, 1996). Understanding sand dunes activity and dynamics not only is relevant to the studies of aeolian processes and the morphological development of different dune types but also has considerable implications for the recognition and interpretation of dunes to which further significance can be linked with paleoclimatic studies (Thomas, 1992). The movement of megadunes should also support information with respect to their formation. However, little is known regarding the movement of megadunes. Firstly, monitoring the movement of megadunes is very difficult largely because they are supposed to move at a rather slow rate. Secondly, it is impossible even to calculate a rough estimate as all the theoretical and empirical formulae developed for the movement rate of dunes have their own specific boundary conditions (Livingstone and Warren, 1996). Understanding megadune movement has to resort to field investigation.

Therefore, this study attempts to obtain information regarding the movement of megadunes in the Badain Jaran Sand Sea that features the tallest megadunes on the Earth (Wang et al., 2020).
The study of megadunes in this sand sea will provide valuable clues to unravel the mystery of megadune formation, and therefore witnessed increasing interest in the last 2 decades (Chen et al., 2004; Dong et al., 2013). The present study aims to unravel more evidences for the megadune formation by testing evidences that exhibit similar mobility with other common dunes. Mobility is a character of shifting dunes. However, it can test existence of the underlying relief, as the underlying bedrock should be exposed due to the megadunes advancement.

\section{PHYSIOGRAPHIC SETTING AND METHODS}

\section{Physiographic Setting}

The Badain Jaran Sand Sea is a part of the Alxa Plateau in western Inner Mongolia, with an area of about $50,000 \mathrm{~km}^{2}$, between latitudes $39^{\circ} 20^{\prime}$ and $42^{\circ} \mathrm{N}$ and longitudes $99^{\circ} 48^{\prime}$ and $104^{\circ} 14^{\prime} \mathrm{E}$ (Yan et al., 2001). The sand sea is bounded to the south by the Heli Mountains, the Beidai Mountains, and the Heishantou Mountains that separate it from the gobis (gravel deserts) of the Hexi Corridor, to the north by the Guezihu wetland, which merges with the black gobis and plains of Mongolia, to the southeast by the Yabrai Mountains, which separate it from the Tengger Desert, and to the west and northwest by the flat lowlands of the Gulunai grassland. The Badain Jaran Sand Sea has a climate of extreme continental desert type according to Köppen's climate classification (Dong et al., 2004), with mean annual precipitation of less than $90 \mathrm{~mm}$, annual potential evaporation of more than $2,500 \mathrm{~mm}$, and mean annual air temperature range from 9.5 to $10.3^{\circ} \mathrm{C}$. The Badain Jaran Sand Sea has a medium wind-energy environment, with the annual sand drift potential (DP) of $281 \mathrm{VU}$ (mean value that calculated at per the result proposed by Zhang et al., 2015), as reported at the nearest meteorological stations.

The outstanding feature that characterizes the Badain Jaran Sand Sea is its megadune-lake landscape, which is comprised of megadunes and more than 100 lakes of different sizes. They are concentrated in the southeast within an area of approximately $4,000 \mathrm{~km}^{2}$. The megadunes generally are $200-300 \mathrm{~m}$ tall, with the tallest megadune exceeding $400 \mathrm{~m}$. These megadunes are classified as complex reversing megadunes developed from compound barchanoid megadunes, with their crests running from northeast $\left(35^{\circ}\right)$ to southwest $\left(215^{\circ}\right)$ (Dong et al., 2009), almost perpendicular to the resultant drift potential. Three megadunes in the hinterland of the megadune area are selected to investigate their advancement (Figure 1).

\section{Methods}

Movement of dunes is controlled by complex factors, but its dependence on dune height has sound scientific basis and is verified by several field observations (Livingstone and Warren, 1996). Megadunes with such height as those observed in the Badain Jaran Sand Sea are supposed to move at such a low rate that it is almost negligible. Hence, commonly implemented monitoring methods such as topographic survey and 

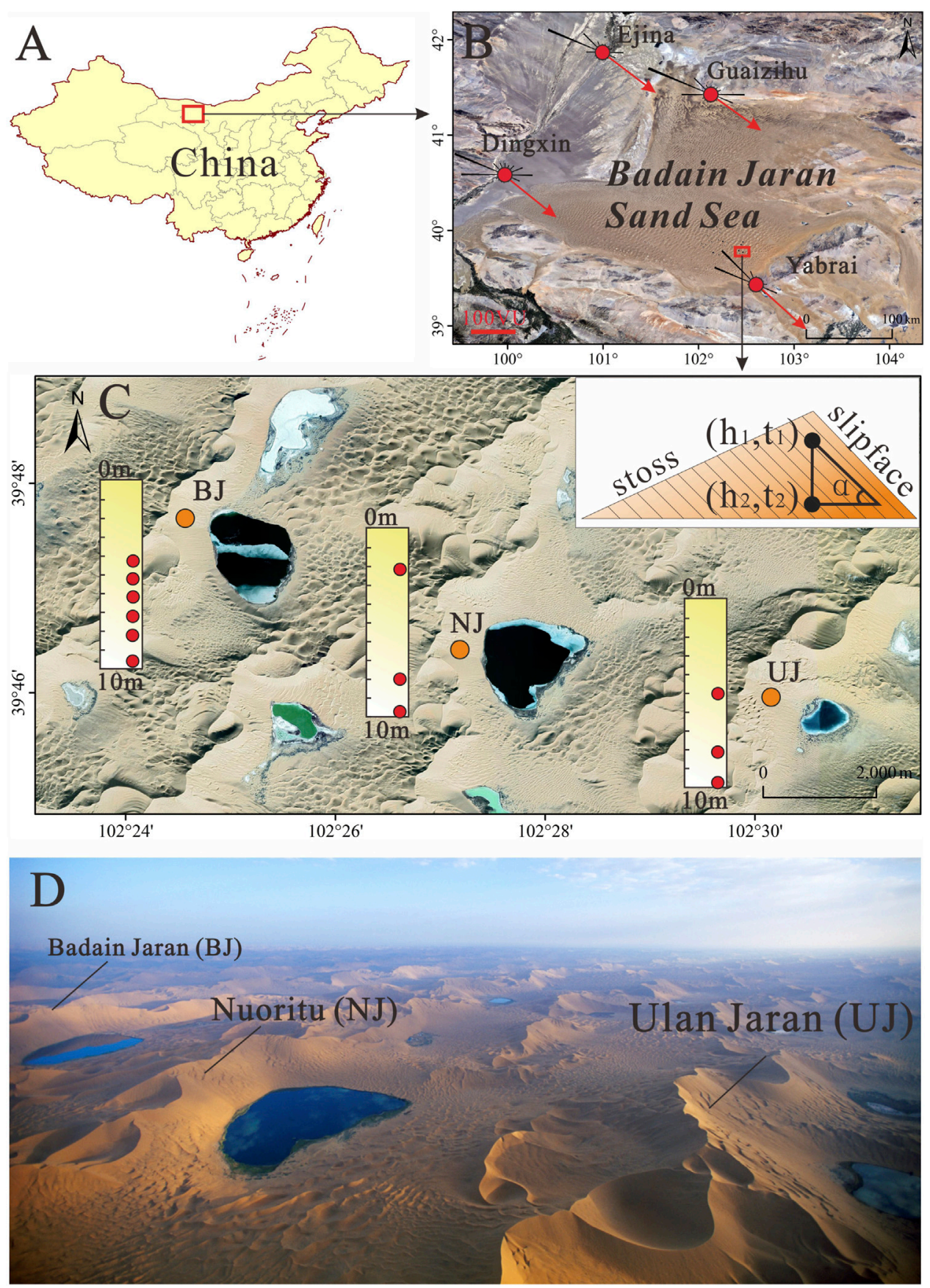

FIGURE 1 | (A, B) Location of the Badain Jaran Sand Sea and wind regime; the sand drift potential is calculated based on the ERA5 Reanalysis Data (www.ecmwf. int). (C) Three megadune drill cores (orange dots) in the Badain Jaran Sand Sea and OSL sampling sites (red dots). The inset graphical representation of the parameters used to estimate the rate of advancement. (D) Aerial image of the three megadunes (Source: Dong et al., 2013).

comparison of remote-sensing images fail to reveal the movement of these megadunes. Therefore, the present study attempts to estimate the advancement rate of megadunes in the Badain Jaran Sand Sea by means of optically stimulated luminescence (OSL) dating that can provide accurate dates of aeolian sediments ( $\mathrm{Yu}$ and Lai, 2012). The mean advancement rate of a megadune can be estimated by dating sediments at different depth on the slipface through Eq. 1 according to a principle illustrated by the inserted diagram in Figure 1. An important assumption is that the advancement of megadunes is realized by wind erosion on the stoss slope and deposition on the leeward slope or slipface. In addition, geometry of the megadune is fairly uniform in the process of its advancement. Rationality of this assumption will be discussed later. 
TABLE 1 | Geographical information of the OSL sampling localities.

\begin{tabular}{|c|c|c|c|c|}
\hline \multirow[t]{2}{*}{ Megadune name } & \multirow[t]{2}{*}{ Height (m) } & \multicolumn{3}{|c|}{ OSL sample location } \\
\hline & & Longitude & Latitude & Altitude (m) \\
\hline Badain Jaran (BJ) & 380 & $102^{\circ} 24^{\prime} 43.96^{\prime \prime} \mathrm{E}$ & $39^{\circ} 47^{\prime} 42.32^{\prime \prime} \mathrm{N}$ & 1245 \\
\hline Nouritu (NJ) & 360 & $102^{\circ} 27^{\prime} 18.43^{\prime \prime} \mathrm{E}$ & $39^{\circ} 46^{\prime} 19.06^{\prime \prime} \mathrm{N}$ & 1244 \\
\hline Ulan Jaran (UJ) & 430 & $102^{\circ} 30^{\prime} 28.58^{\prime \prime} \mathrm{E}$ & $39^{\circ} 45^{\prime} 59.26^{\prime \prime} \mathrm{N}$ & 1315 \\
\hline
\end{tabular}

\begin{tabular}{|c|c|c|c|c|c|c|c|c|}
\hline $\begin{array}{l}\text { Sample } \\
\text { ID }\end{array}$ & $\begin{array}{l}\text { Depth } \\
\text { (m) }\end{array}$ & U (ppm) & Th (ppm) & K (\%) & $\begin{array}{c}\text { Water } \\
\text { content }(\%)\end{array}$ & De (Gy) & $\begin{array}{c}\text { Dose } \\
\text { rate }\left(G y k^{-1}\right)\end{array}$ & $\begin{array}{l}\text { OSL age } \\
\text { (ka) }\end{array}$ \\
\hline BJ-01 & 4.3 & $1.20 \pm 0.08$ & $3.58 \pm 0.17$ & $1.47 \pm 0.05$ & 1.67 & $0.46 \pm 0.04$ & $2.18 \pm 0.06$ & $0.22 \pm 0.02$ \\
\hline BJ-02 & 5.3 & $1.08 \pm 0.08$ & $3.23 \pm 0.18$ & $1.63 \pm 0.04$ & 2.98 & $0.57 \pm 0.06$ & $2.16 \pm 0.05$ & $0.26 \pm 0.03$ \\
\hline BJ-03 & 6.3 & $1.44 \pm 0.09$ & $3.57 \pm 0.17$ & $1.60 \pm 0.04$ & 0.78 & $0.87 \pm 0.06$ & $2.29 \pm 0.05$ & $0.38 \pm 0.03$ \\
\hline BJ-04 & 7.3 & $1.2 \pm 0.08$ & $4.36 \pm 0.19$ & $1.69 \pm 0.04$ & 1.39 & $1.06 \pm 0.09$ & $2.35 \pm 0.05$ & $0.45 \pm 0.04$ \\
\hline BJ-05 & 8.3 & $1.18 \pm 0.08$ & $3.57 \pm 0.18$ & $1.44 \pm 0.05$ & 1.14 & $1.02 \pm 0.11$ & $2.04 \pm 0.05$ & $0.50 \pm 0.06$ \\
\hline BJ-06 & 9.6 & $1.08 \pm 0.08$ & $3.52 \pm 0.19$ & $1.48 \pm 0.05$ & 1.08 & $1.15 \pm 0.05$ & $2.02 \pm 0.05$ & $0.57 \pm 0.03$ \\
\hline NJ-01 & 2.1 & $1.25 \pm 0.09$ & $4.36 \pm 0.20$ & $1.58 \pm 0.04$ & 2.14 & $0.35 \pm 0.22$ & $2.32 \pm 0.05$ & $0.15 \pm 0.09$ \\
\hline NJ-02 & 8.0 & $0.95 \pm 0.08$ & $3.32 \pm 0.17$ & $1.30 \pm 0.05$ & 0.43 & $0.64 \pm 0.10$ & $1.88 \pm 0.06$ & $0.34 \pm 0.05$ \\
\hline $\mathrm{NJ}-03$ & 9.7 & $1.10 \pm 0.08$ & $3.72 \pm 0.19$ & $1.42 \pm 0.05$ & 0.36 & $0.86 \pm 0.09$ & $2.023 \pm 0.06$ & $0.42 \pm 0.05$ \\
\hline UJ-01 & 5.0 & $0.97 \pm 0.08$ & $2.93 \pm 0.18$ & $1.34 \pm 0.05$ & 1.43 & $2.16 \pm 0.13$ & $1.88 \pm 0.06$ & $1.15 \pm 0.08$ \\
\hline UJ-02 & 8.1 & $1.00 \pm 0.08$ & $3.69 \pm 0.17$ & $1.39 \pm 0.05$ & 2.05 & $4.27 \pm 0.37$ & $1.94 \pm 0.06$ & $2.20 \pm 0.20$ \\
\hline UJ-03 & 9.7 & $1.14 \pm 0.08$ & $3.62 \pm 0.17$ & $1.40 \pm 0.05$ & 2.33 & $5.34 \pm 0.31$ & $1.97 \pm 0.06$ & $2.72 \pm 0.18$ \\
\hline
\end{tabular}

$$
D=\left(h_{2}-h_{1}\right) /\left(t_{2}-t_{1}\right) \tan \alpha
$$

where $D$ is the mean advancement rate during the period between time $t_{1}$ and $t_{2}, h_{1}$ and $h_{2}$ are the depth corresponding to $t_{1}$ and $t_{2}$, respectively, and $\alpha$ is the angle of the slipface, about $30^{\circ}$. Hence, the advancement rate of megadunes can be estimated by dating aeolian sediments at different depths on the slipface.

Sediments at different depth on slipfaces of the three megadunes (Figure 1; Table 1) were sampled according to the OSL dating protocols. A sampling hand drill with an inner diameter of $100 \mathrm{~mm}$ was driven into the slipfaces of megadunes to extract underground sediment cores. A $200 \mathrm{~mm}$ long and $50 \mathrm{~mm}$ wide stainless tube was inserted to the sediment core to obtain OSL samples. The tubes containing sediment samples were sealed by aluminum foil and black plastic film. We finally collected 6 samples in the Badain Jaran megadune, and 3 samples in the Nuoritu and Ulan Jaran megadunes, respectively. Both ends (about $30 \mathrm{~mm}$ ) of the sediment in the tube that were thought to be exposed were excluded in OSL dating.

The content of $\mathrm{U}, \mathrm{Th}$, and $\mathrm{K}$ of the OSL dating samples was measured by neutron activation method in China Institute of Atomic Energy. The moisture content was measured by oven drying method. OSL dating was carried out in the Shaanxi Normal University (Wang et al., 2021). We selected $90-125 \mu \mathrm{m}$ quartz grains by wet sieving as the target measuring particles. Other detailed pretreatment procedures refer to Zhang et al. (2019). The annual dose rate of cosmic ray was calculated based on the parameters and equations proposed by Prescott and Hutton (1994). Equivalent dose of quartz originating from ceramics was obtained by OSL single aliquot regenerative dose (SAR) method, measured at $260^{\circ} \mathrm{C}$ of

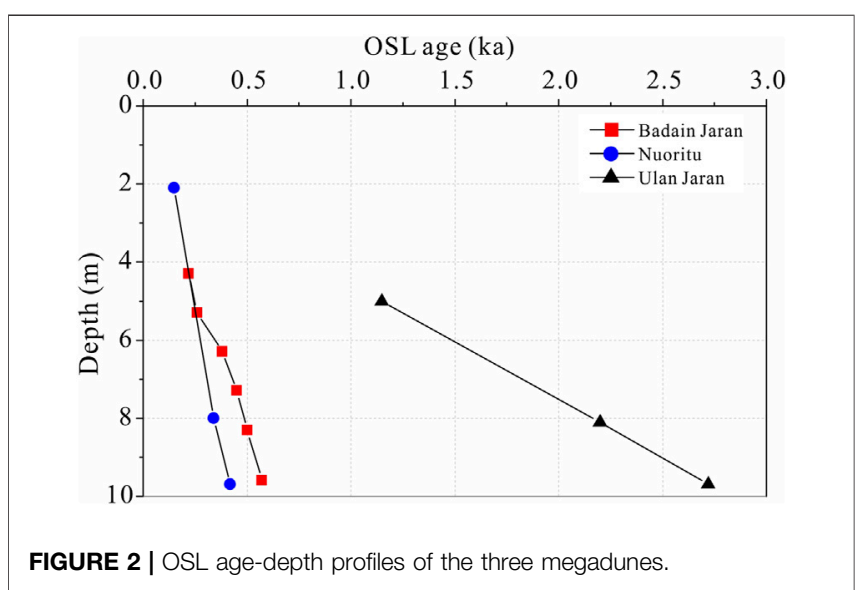

preheat and $220^{\circ} \mathrm{C}$ of cutheat. The ages of quartz particles were derived based on annual dose rate and equivalent dose.

\section{RESULTS AND DISCUSSION}

The environmental radioactivity and OSL dating results of the three megadunes are listed in Table 2. The drilling depth of the three megadunes is similar, around $10 \mathrm{~m}$ (the maximum depth of the drill). However, the time span they cover is different, implying that the megadunes have different advancement rate. The taller is the megadune, the longer is the time span. The $10 \mathrm{~m}$ drill could drill through a stratum up to $2.7 \mathrm{ka}$ old on the Ulan Jaran 
megadune, but only about $0.4 \mathrm{ka}$ on the Nuoritu megadune. Consequently, the megadunes exhibit advancement rate on different time scale. The reliability of the OSL dating results is suggested in two aspects. Firstly, the OSL age-depth profiles of the three megadunes are similar (Figure 2), following a reasonable linear relationship reasonably well considering that the advancement rate of megadunes might have varied with time. Secondly, the Nuoritu megadune and Badain Jaran megadune demonstrate similar variation trend in advancement rate for the same period. Hence, we are confident that the OSL dating in this study provides reliable estimate pertaining to megadune advancement rate in the Badain Jaran Sand Sea.

Another question arises whether the sediments of different ages represent megadune advancement, involving the basic assumption to estimate the megadune advancement rate as mentioned in Methods Section. Net erosion of windward slope of the megadunes is manifested by the exposed stratification in several localities of the windward slopes, which are inclined with the same direction and angle (repose angle) of the slipfaces. Stratigraphic detections conducted on the windward slopes of two typical megadunes by Ground Penetrating Radar (GPR) revealed stratification consistent with the slipfaces of the megadunes, although the stratification in the upper sections was complicated by reversed crests (Li et al., 2009). The megadunes in Badain Jaran Sand Sea have been experiencing wind erosion on the windward slopes and deposition on the leeward slopes (slipfaces), resulting in overall advancement.

\section{Advancement Rate of Megadunes}

The advancement rate of megadunes at the order of meter per hundred years is much slower than the dunes commonly observed. Such a slow advancement rate can hardly be observed by conventional methods. Factors responsible for the slow advancement possibly include large size of the megadunes and the wind regime. Megadunes in the Badain Jaran Sand Sea are complex reversing megadunes. Their primary slipfaces are oriented towards the southeast in response to the dominant northwestern wind, and secondary slipfaces are oriented towards the northwest in response to the secondary southeastern wind (Dong et al., 2004). Hence, the megadunes advance towards southeast. The Badain Jaran Sand Sea generally has medium wind energy environments (Zhang et al., 2015). It usually has a wide unimodal to acute bimodal wind regime with intermediate directional variability characterized by RDP/DP (RDP is resultant drift potential, DP is drift potential) ranging from 0.5 to 0.8 (Dong et al., 2004). While the prevailing northwestern wind results in a general advancement toward the southeast, frequent southeastern wind especially in summer results in the reversed crest zones, at top 40-60 m of the megadunes (Dong et al., 2009). This reversed crest zone is the most active part of the megadune, and migrates back and forth in response to variations in wind direction. In addition, it forms reversed slipface by the southeastern wind. The reversed slipface partly offsets megadune advancement, though it cannot alter the general advancement as it consumes energy for the prevailing northwestern wind to adjust the slipface.
The slow advancement rate also partly contributes to the heightening of megadunes. Recent observations reveal that the megadune-lake system exists as a unique local air circulation with radiation of wind from lake throughout the year (Figure 3, unpublished data), resulting climbing sands on the slipfaces, retarding advancement, and heightening of megadunes. Therefore, the slow advancement rate of the megadunes in Badain Jaran Sand Sea is an aspect reflecting their formation mechanism. Morphology, movement, and lakes are interrelated to form this unique megadune-lake system.

\section{Advance Rate-Height Relationship of Megadunes}

Complex factors may influence the movement of sand dunes but the factors that influence the advancement of megadunes in the Badain Jaran Sand Sea due to the absence of vegetation and the underlying obstacles (Dong et al., 2009). In this context, it is meaningful to discuss the relationship between advancement rate and height of megadunes like other shifting dunes, although the advancement rate is solely available for three megadunes. Theories regarding the movement of barchans are followed here to understand the advancement of megadunes in the Badain Jaran Sand Sea. The age-depth profiles suggest that it is imperative to discuss the megadune advancement rate based on the average advancement rate of the three megadunes, though different megadunes represent different time periods. The longest time span that the advancement rate represents is less than $3 \mathrm{ka}$. The Late Holocene dune reaction stage in the arid regions of China (Yang, 2001), and the factors that influence megadune advancement can be considered relatively stable so that dune advancement rate did not vary widely with time (Figure 4 ). The following discussion on the relationship between advancement rate and megadune height and its geomorphologic implications are based on the average advancement rate.

A basic formula (Eq. 2) relating the movement rate and height has been derived for transverse dunes (Simons et al., 1965).

$$
V_{\mathrm{d}}=q / k H \rho_{\mathrm{p}}
$$

where $V_{\mathrm{d}}$ is the movement rate of a dune, $q$ is the transport rate of the sand trapped by the slipface, approximately equaling the transport rate on the stoss slope $k=A / L H$, where $A$ is the twodimensional cross-sectional area of the dune, and $L$ is its wavelength (distance between neighboring dunes), $H$ is the height of the dune, and $\rho_{\mathrm{p}}$ is the bulk density of the sand in the dune. Variations of this basic formula have been produced for different purposes, but the fact that the movement rate of dunes changes linearly with the reciprocal of dune height is adequately confirmed by field observations (Figure 5). The curves in Figure 5 represent a function $V_{\mathrm{d}}=a+b / H$, where $\mathrm{a}$ and $\mathrm{b}$ are regressive coefficients. However, uncertainty still exists on the size-movement curve at either extreme of the size range. Previous observations in Figure $\mathbf{5}$ only represented dunes lower than $100 \mathrm{~m}$. It is suggested that larger dunes seem to reach a plateau in their rate of movement beyond which the size has no role. This is possibly due to greater wind speed-up. 


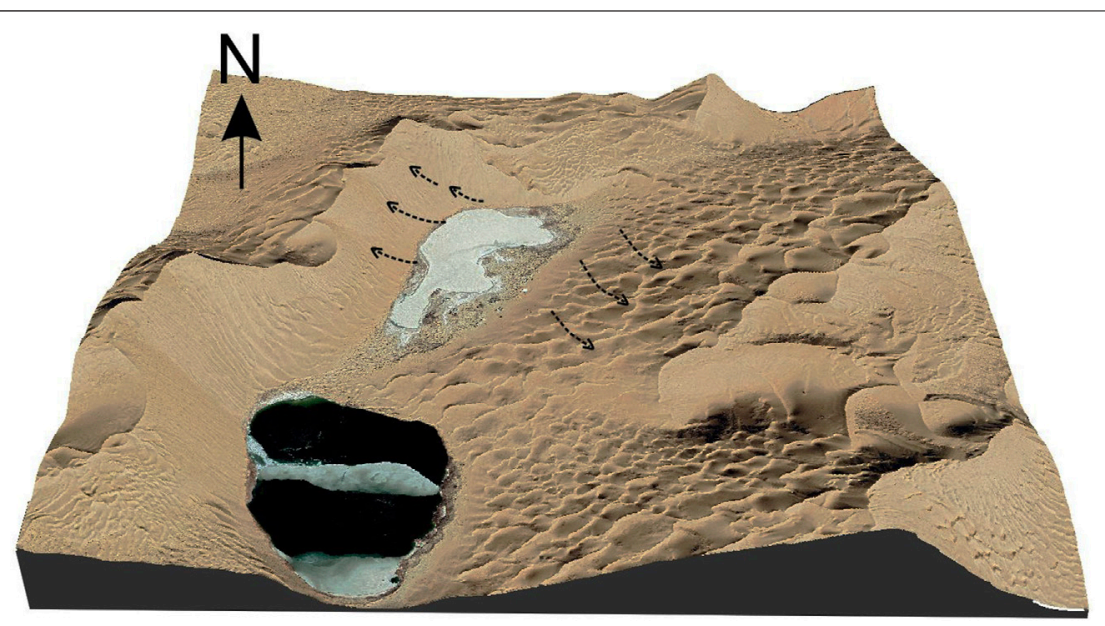

FIGURE 3 | Observed local air circulation that radiates from the interdune lakes (based on the unpublished data collected from wind towers).
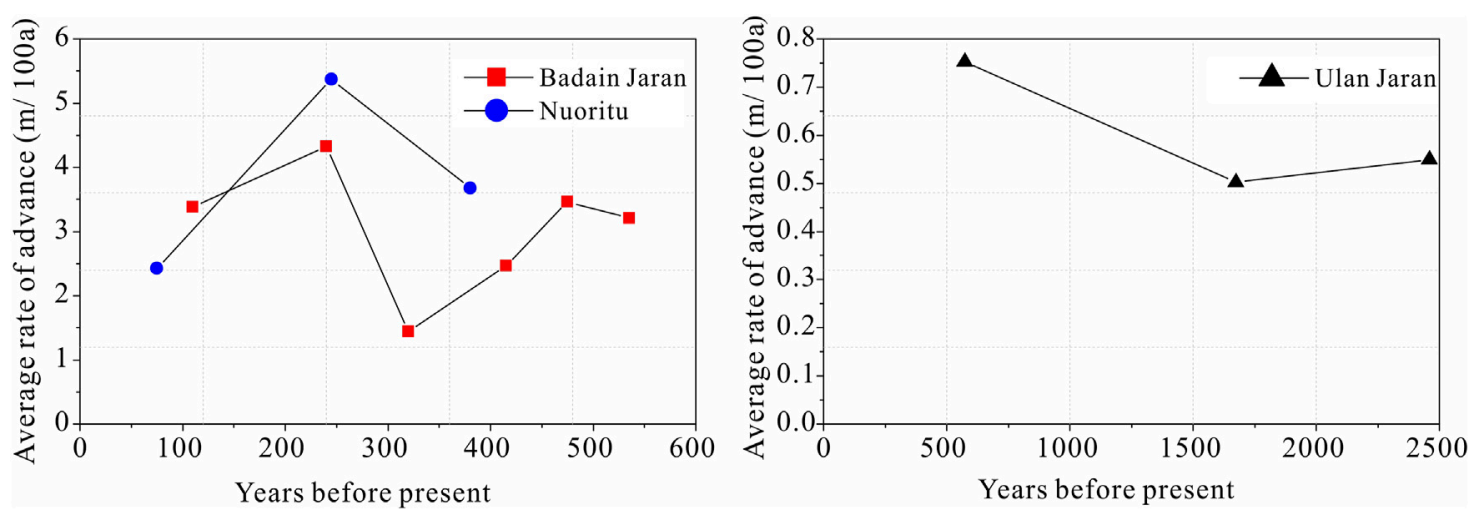

FIGURE 4 | Average advancement rate of the megadunes in different periods.

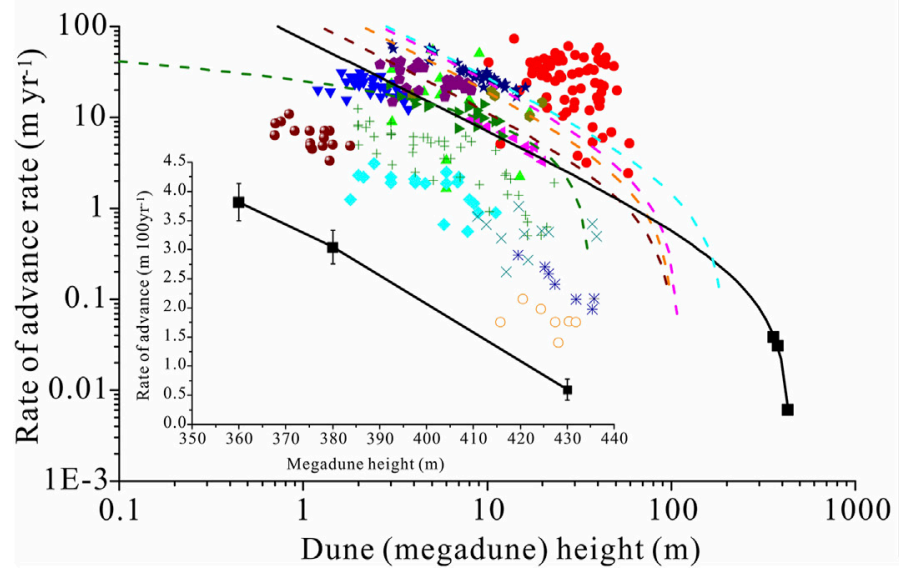

- Badain Jaran mega-dunes, China (This study)

Bodele (Vermeesch and Drake, 2008)

A Kelso (Lancaster, 1994)

- Mauritania (Ould Ahmedou et al., 2007)

Victoria (Bourke et al., 2009)

4 Saudi Arabia (Fryberger et al.,1984)

- Saudi Arabia (Al-Hinal, 1988)

- Egypt (Beadnel, 1910)

$\star$ Mauritania (Coursin, 1964)

- Salton (Long and Sharp, 1964)

- Northern Taklimakan (Dong et al.,2000)

+ Southern Taklimakan (Zhu et al.,1981)

× Mars ripple: Lee front (Bridges et al.,2012)

* Mars ripple: Upwind (Bridges et al.,2012)

Mars ripple: Downwind (Bridges et al.,2012)

- - Peru (Finkel,1959)

- - - Arequipa, Peru (Hastenrath, 1967)

- - Imperial Valley of California, USA (Norris, 1966)

Badain Jaran megadunes, China (This study)

Abiodh, Mauritania (Coursin, 1964)

- - Saudi Arabia (Al-Hinai, 1988)

FIGURE 5 | Measured rates of transverse dune movement and the estimated advancement rate of megadunes in the Badain Jaran Sand Sea as a function of height. (Beadnell, 1910; Finkel, 1959; Coursin, 1964; Long and Sharp, 1964; Norris, 1966; Hastenrath, 1967; Zhu et al., 1981; Fryberger et al., 1984; Al-Hinai, 1988; Lancaster, 1994; Dong et al., 2000; Ould Ahmedou et al., 2007; Vermeesch and Drake, 2008; Bourke et al., 2009; Bridges et al., 2012) 
Consequently, it is hypothesized that the relationship between movement rate and dune height should be exponential rather than linear (Sarnthein and Walger, 1974). However, few observations are available to confirm this. The advancement of the tallest megadunes on the Earth in the Badain Jaran Sand Sea gives us an opportunity to test the above hypothesis.

Figure 5 displays that the relationship between advancement rate and height of the three megadunes fall on a curve that fits the above linear function effectively. This linear relationship demonstrates that the slow advancement rate of Ulan Jaran megadune mostly resulted from its great height. However, several geomorphologic implications exist in this regard. Firstly, the tallest megadunes in the Badain Jaran Sand Sea experience similar advancement to sand dunes commonly observed. This is also verified by sedimentary structures of the megadunes, which are dominated by slipface beddings inclined towards the advancement direction and lack the gently-inclined stoss beddings (Yang, 2001; Li et al., 2009). Advancement of the megadunes is the consequence of piecemeal deflation on the windward slope, and of deposition in the lee side. Secondly, the possibility that the underlying relief controls the development of megadunes can be negated because no exposure of underlying bedrocks is observed on stoss side of the megadunes, which have undergone a long history of deflation. Increasing evidences support the fact that no bedrock relief underlies the megadunes (Yang et al., 2011). Thirdly, evidence from megadune advancement combined with previous morphometric features proves that the development of megadunes is controlled dominantly by wind rather than other factors such as the underlying relief and ground water as proposed previously (Dong et al., 2009).

\section{CONCLUSION}

It is suggested that the megadunes in Badain Jaran Sand Sea do advance, although their advancement rate is rather slow. The advancement of megadunes revealed in this study has several important implications:

1) The advancement of the megadunes explains the reason why the windward slopes of megadunes in Badain Jaran Sand Sea are dominated by slipface beddings inclined towards the advancement direction and lack the gently-inclined stoss beddings. In fact, the stoss beddings are preserved much less in fossil aeolian sand.

2) The megadunes in Badain Jaran Sand Sea have been experiencing piecemeal deflation on the windward slope, and of deposition in the lee. This justifies the assumption based on which the advancement rate of megadunes was

\section{REFERENCES}

Ai-Hinai, K. G. (1988). Quaremary Aeolian Sand Mapping in Saudi Arabia, Using Remotely-Sensed Imagery. London, UK: PhD, University of London. estimated by dating the sediments at different depth of the slipfaces. The OSL dating method proves to be a good alternative to estimate the slow advancement rate such as that of the megadunes due to failure of the conventional methods.

3) The relationship between the advancement rate and height confirmed previously for dunes is extended to complex reversing megadunes. The large size of megadunes and the wind regime are largely responsible for the slow advancement rate of the megadunes in the Badain Jaran Sand Sea. In addition, unique local air circulation that radiates to form lakes partly retards megadune advancement and contributes to heightening of the megadunes. Morphology, movement, and lakes are interrelated to form the unique megadune lake system.

4) The advancement of megadunes adds more evidence to support the fact that the development of megadunes in the Badain Jaran Sand Sea is controlled dominantly by wind rather than other factors such as the underlying relieves, ground water, etc. However, more robust evidences are waiting for the deeper drill cores.

\section{DATA AVAILABILITY STATEMENT}

The original contributions presented in the study are included in the article/Supplementary material. Further inquiries can be directed to the corresponding author.

\section{AUTHOR CONTRIBUTIONS}

PD wrote the manuscript and done the field work. AL revised the manuscript and designed and did the field work. YZ did the OSL experiment.

\section{FUNDING}

This research was funded by the Fundamental Research Funds for the Central Universities (GK202103144).

\section{ACKNOWLEDGMENTS}

We are grateful to Prof. Luo Wanyin and Prof. Zhang Zhengcai (Northwest Institute of Eco-Environment and Resources, Chinese Academy of Sciences) for their assistance with our fieldwork. We also extend our deepest respect and appreciation to all the scientists who made substantial contributions to previous research in the Badain Jaran Sand Sea.

Beadnell, H. J. L. (1910). The Sand-Dunes of the Libyan Desert. Geographical J. 36, 367-395. doi:10.2307/1777337

Bourke, M. C., Ewing, R. C., Finnegan, D., and McGowan, H. A. (2009). Sand Dune Movement in the Victoria Valley, Antarctica. Geomorphology 109 (3), 148-160. doi:10.1016/j.geomorph.2009.02.028 
Bridges, N. T., Ayoub, F., Avouac, J.-P., Leprince, S., Lucas, A., and Mattson, S. (2012). Earth-like Sand Fluxes on Mars. Nature 485 (7398), 339-342. doi:10.1038/nature11022

Chen, J. S., Li, L., Wang, J. Y., Barry, D. A., Sheng, X. F., Gu, W. Z., et al. (2004). Groundwater Maintains Dune Landscape. Nature 432, 459-460. doi:10.1038/ 432459 a

Coursin, A. (1964). Observations et expériences faites en avril et mai 1956 sur les barkhans du Souehel el Abiodh (région est de Port-Étienne). Paris, France: Bulletin: Institut Française de l'Afrique Noire.

Dong, Z., Qian, G., Luo, W., Zhang, Z., Xiao, S., and Zhao, A. (2009). Geomorphological Hierarchies for Complex Mega-Dunes and Their Implications for Mega-Dune Evolution in the Badain Jaran Desert. Geomorphology 106 (3), 180-185. doi:10.1016/j.geomorph.2008.10.015

Dong, Z., Qian, G., Lv, P., and Hu, G. (2013). Investigation of the Sand Sea with the Tallest Dunes on Earth: China's Badain Jaran Sand Sea. Earth-Science Rev. 120, 20-39. doi:10.1016/j.earscirev.2013.02.003

Dong, Z., Wang, T., and Wang, X. (2004). Geomorphology of the Megadunes in the Badain Jaran Desert. Geomorphology 60 (1), 191-203. doi:10.1016/ j.geomorph.2003.07.023

Dong, Z., Wang, X., and Chen, G. (2000). Monitoring Sand Dune advance in the Taklimakan Desert. Geomorphology 35 (3), 219-231. doi:10.1016/S0169555X(00)00039-8

Finkel, H. J. (1959). The Barchans of Southern Peru. J. Geology. 67 (6), 614-647. doi: $10.1086 / 626622$

Fryberger, S. G., Al-Sari, A. M., Clisham, T. J., Rizvi, S. A. R., and Al-Hinai, K. G. (1984). Wind Sedimentation in the Jafurah Sand Sea, Saudi Arabia. Sedimentology 31, 413-431. doi:10.1111/j.1365-3091.1984.tb00869.x

Goudie, A. S. (2004). Encyclopedia of Geomorphology. London: Routledge.

Hastenrath, S. L. (1967). The Barchans of the Arequipa Region, Southern Peru. $Z$. Geomorphol. 11 (3), 300-331. doi:10.1086/626622

Lämmel, M., Meiwald, A., Yizhaq, H., Tsoar, H., Katra, I., and Kroy, K. (2018). Aeolian Sand Sorting and Megaripple Formation. Nat. Phys 14 (7), 759-765. doi:10.1038/s41567-018-0106-Z

Lancaster, N. (1994). Controls on Aeolian Activity: Some New Perspectives from the Kelso Dunes, Mojave Desert, California. J. Arid Environments 27 (2), 113-125. doi:10.1006/jare.1994.1052

Li, X., Wang, Z., Chen, F., Lancaster, N., Li, Z., Li, G., et al. (2009). Deposition of Transverse Dune Mountains in Badain Jaran Desert. Quat. Sci. 29 (4), 797-805. doi:10.3969/j.issn.10017410.2009.04.16

Livingstone, I., and Warren, A. (2019). Aeolian Geomorphology : A New Introduction. Hoboken: John Wiley \& Sons.

Livingstone, I., and Warren, A. (1996). Aeolian Geomorphology: An Introduction. London: Longman.

Long, J. T., and Sharp, R. P. (1964). Barchan-dune Movement in Imperial Valley, California. Geol. Soc. America Bull. 75 (2), 149-156. doi:10.1130/00167606(1964)75[149:bmiivc]2.0.co;2

Lou, T. (1962). The Formation and Utilization of the Desert between Minqing and Badain Monastery. Beijing: Science Press.

Norris, R. M. (1966). Barchan Dunes of Imperial Valley, California. J. Geology. 74 (3), 292-306. doi:10.1086/627164

Ould Ahmedou, D., Ould Mahfoudh, A., Dupont, P., Ould El Moctar, A., Valance, A., and Rasmussen, K. R. (2007). Barchan Dune Mobility in Mauritania Related to Dune and Interdune Sand Fluxes. J. Geophys. Res. 112 (F2). doi:10.1029/2006JF000500

Pelletier, J. D. (2009). Controls on the Height and Spacing of Eolian Ripples and Transverse Dunes: A Numerical Modeling Investigation. Geomorphology 105 (3), 322-333. doi:10.1016/j.geomorph.2008.10.010

Phillips, J. D. (1992). Nonlinear Dynamical Systems in Geomorphology: Revolution or Evolution? Geomorphology 5 (3), 219-229. doi:10.1016/0169555X(92)90005-9

Prescott, J. R., and Hutton, J. T. (1994). Cosmic ray Contributions to Dose Rates for Luminescence and ESR Dating: Large Depths and Long-Term Time Variations. Radiat. Meas. 23 (2), 497-500. doi:10.1016/1350-4487(94)90086-8

Qian, G., Yang, Z., Tian, M., Dong, Z., Liang, A., and Xing, X. (2021). From Dome Dune to Barchan Dune: Airflow Structure Changes Measured with Particle
Image Velocimetry in a Wind Tunnel. Geomorphology 382, 107681. doi:10.1016/j.geomorph.2021.107681

Richards, K. J. (1980). The Formation of Ripples and Dunes on an Erodible Bed. J. Fluid Mech. 99 (3), 597-618. doi:10.1017/S002211208000078X

Rozier, O., Narteau, C., Gadal, C., Claudin, P., and Courrech du Pont, S. (2019). Elongation and Stability of a Linear Dune. Geophys. Res. Lett. 46 (24), 14521-14530. doi:10.1029/2019GL085147

Sarnthein, M., and Walger, E. (1974). Der äolische Sandstrom aus der W-Sahara zur Atlantikküste. Geol. Rundsch. 63 (3), 1065-1087. doi:10.1007/BF01821323

Simons, D. B., Richardson, E. V., and Nordin, C. F., Jr (1965). Bedload Equation for Ripples and Dunes. Professional Paper. Washington, DC: US Government Printing Office.

Sun, P., and Sun, Q. (1964). The Hydrological Geology of the Western Inner Mongolia. Beijing: Science Press.

Thomas, D. S. G. (1992). Desert Dune Activity: Concepts and Significance. J. Arid Environments 22 (1), 31-38. doi:10.1016/S0140-1963(18)30654-2

Vermeesch, P., and Drake, N. (2008). Remotely Sensed Dune Celerity and Sand Flux Measurements of the World's Fastest Barchans (Bodélé, Chad). Geophys. Res. Lett. 35 (24). doi:10.1029/2008GL035921

Wang, H., Huang, C. C., Pang, J., Zhou, Y., Cuan, Y., Guo, Y., et al. (2021). Catastrophic Flashflood and Mudflow Events in the Pre-historical Lajia Ruins at the Northeast Margin of the Chinese Tibetan Plateau. Quat. Sci. Rev. 251, 106737. doi:10.1016/j.quascirev.2020.106737

Wilson, I. G. (1972). Aeolian Bedforms-Their Development and Origins. Sedimentology 19 (3-4), 173-210. doi:10.1111/j.1365-3091.1972.tb00020.x

Yan, M., Guangqian, W., Baosheng, L., and Guangrong, D. (2001). Formation and Growth of High Megadunes in Badain Jaran Desert. Acta Geographica Sinica 56 (1), 83-91. doi:10.11821/xb200101010

Yang, X. (2001). Landscape Evolution and Palaeoclimate in the Deserts of Northwestern China, with a Special Reference to Badain Jaran and Taklamakan. Chin.Sci.Bull. 46 (1), 6-10. doi:10.1007/BF03187228

Yang, X., Scuderi, L., Liu, T., Paillou, P., Li, H., Dong, J., et al. (2011). Formation of the Highest Sand Dunes on Earth. Geomorphology 135 (1), 108-116. doi:10.1016/j.geomorph.2011.08.008

Yu, L., and Lai, Z. (2012). OSL Chronology and Palaeoclimatic Implications of Aeolian Sediments in the Eastern Qaidam Basin of the Northeastern QinghaiTibetan Plateau. Palaeogeogr. Palaeoclimatol. Palaeoecol. 337-338, 120-129. doi:10.1016/j.palaeo.2012.04.004

Zhang, Y., Huang, C. C., Shulmeister, J., Guo, Y., Liu, T., Kemp, J., et al. (2019). Formation and Evolution of the Holocene Massive Landslide-Dammed Lakes in the Jishixia Gorges along the Upper Yellow River: No Relation to China's Great Flood and the Xia Dynasty. Quat. Sci. Rev. 218, 267-280. doi:10.1016/ j.quascirev.2019.06.011

Zhang, Z., Dong, Z., and Li, C. (2015). Wind Regime and Sand Transport in China's Badain Jaran Desert. Aeolian Res. 17, 1-13. doi:10.1016/j.aeolia.2015.01.004

Zhu, Z., Chen, Z., Wu, Z., Li, J., Li, B., and Wu, G. (1981). A Study on the Sand Dune Geomorphology of Taklimakan Desert. Beijing: Science Press.

Conflict of Interest: The authors declare that the research was conducted in the absence of any commercial or financial relationships that could be construed as a potential conflict of interest.

Publisher's Note: All claims expressed in this article are solely those of the authors and do not necessarily represent those of their affiliated organizations, or those of the publisher, the editors and the reviewers. Any product that may be evaluated in this article, or claim that may be made by its manufacturer, is not guaranteed or endorsed by the publisher.

Copyright (C) 2022 Dong, Liang and Zhou. This is an open-access article distributed under the terms of the Creative Commons Attribution License (CC BY). The use, distribution or reproduction in other forums is permitted, provided the original author(s) and the copyright owner(s) are credited and that the original publication in this journal is cited, in accordance with accepted academic practice. No use, distribution or reproduction is permitted which does not comply with these terms. 